\title{
Join the Holy Spirit on Zoom
}

African Pentecostal churches and their liturgical practices during COVID-19

DOI: https://doi.org/10.30664/ar.107728

(c)(1) Attribution 4.0 International (CC BY 4.0)

$\mathrm{T}$ he COVID-19 global pandemic impacted all social relations, including the way religious communities engage in worship services. Due to strict social distancing protocols, the only viable solution for many congregations was online worship. This article investigates how platforms in cyberspace, such as Zoom, can provide a substitute for the core religious practices found in physical worship services, particularly for African Pentecostal believers who rely heavily on the aesthetic and sensory experience of their religious environment. Drawing on the theoretical concept of affordance, it is argued that digital affordances such as the chat box and emojis are used by believers to communicate affective moments arising from the sensory experience of worship. Members of the congregation become 'digital spiritual hype people' who render support to leaders in order to create and regenerate an affective environment where the presence of the Holy Spirit can be felt. The Holy Spirit, a fundamental pillar for Evangelical Christians, is understood as an embedded presence within the digital infrastructure. The internet connection, the phone and computers and screens are all re-appropriated as spiritual tools through which miraculous healing can be dispensed to believers in need. This research stands at a critical juncture between what might be termed the 'pre-COVID era' and the 'post-COVID era'. As vaccination plans continue to roll out and social distancing measures are slowly being lifted, a 'post-COVID era' for African Pentecostals means negotiating the boundaries between online and offline spaces to fulfil core religious practices.

\section{Introduction}

On day one of the national lockdown in Italy our senior pastor sent a text in the WhatsApp group informing church members that the Italian government had banned all social gatherings across the nation. Effective immediately, all churches would be closed and members would not be allowed to meet with one another due to the strict measures imposed. ${ }^{1}$ The message sent panic waves across the congregations, and the church leadership board called for an emergency meeting to find a solution to the problem at hand. After days of deliberation, the leaders proposed that the congregation meet online to worship. My church has a small congregation of 30 to 50 believers, so the digital platform needed to recreate, as much as possible, the sense of close-

1 The first cases of COVID-19 were initially detected in northern Italy in the early days of 2020. By February 2020 Lombardy became the centre of the crisis, thus resulting in a lockdown of the entire region. Subsequently, as the number of infections spread to the neighbouring regions, the Italian government instituted a national lockdown on 9 March 2020. The governmental decree dubbed 'Io Resto a Casa' (I stay home), banned all forms of social interactions, including religious gatherings. 
ness and intimate connection that physical worship provided. Moreover, it required a smart and simple set up so that members who were less technologically savvy would be encouraged to join the service. Among the multitude of choices available on the application market, our pastor proposed Zoom and Free Conference Call. Both platforms are equipped with a userfriendly interface, and, unlike other similar applications, they do not possess a gatekeeper structure and multi-level access. Moreover, these are platforms that do not require a network of existing users in order to enjoy the full benefits of the application. ${ }^{2}$ By April 2020, many church leaders across the region had learned about the benefits of Zoom, and throughout the network of African Pentecostal churches it was being heralded as the solution to church closures. The result was a new form of digital evangelism that emerged in various churches as believers used social media to share Zoom links to promote church activities. I received many such invitations, and as I began to attend online church services, I took note of the changes that were unfolding and how believers were engaging in this new (to them) digital arena.

This article analyses the findings of a netnographic (internet-based ethnographic) study involving African Pentecostal worshippers in Italy as they attempted to recreate religious practices on a digital platform,

2 Zoom is a cloud-based software which provides virtual video communication. Users are not required to set up an account as they receive a URL link with an invitation to join a meeting. Free Conference Call is an international conference call service which allows meeting attendees to dial in using toll-free call numbers from specific countries or by using an internet connection. Here too users can join a church service without the need to set up an account. and the impact of this on believers' spiritual fulfillment. The present research stands at a critical juncture between what might be known as the 'pre-COVID era' and the 'post-COVID era'. Thanks to the progress in the roll out of vaccines, lockdowns and social distancing mandates are easing and religious communities across the globe are slowly returning to physical fellowship. Nevertheless, the lesson learnt from the 'COVID era' is that religious communities do not need to rely solely on physical connections for all the important elements in their liturgy. As such, digital fellowship might ultimately prove to be a bona fide mode of worship for future generations of believers.

\section{Characteristic features of African Pentecostalism}

Pentecostalism is a branch of Christianity which emphasises a transformative experience through the Holy Spirit as spiritual phenomena such as glassolalia, prophesies, visions, healing, and miracles are understood as being on a historical continuum with the experiences of the early churches found in the Acts of the Apostles, as well as signifying the manifestation of God's presence in the life of the believer (AsamoahGyadu 2005a). Pentecostalism spread widely in Africa in the late 1970 s following missionary endeavours in Nigeria and Ghana, and subsequently across the rest of the continent. In adapting to the traditional practices of the indigenous population, who yearned for a deeper spiritual connection with the divine, the doctrine assumed a new identity more centred on the role of the Holy Spirit (p.13). Within the new cultural landscape, believers placed greater emphasis on the spiritual phenomena, which, according to their own interpretation, constituted spiritual gifts that had the potential to eradicate evil and achieve 
miracles (Buttici 2012; Formenti 2007; Asamoah-Gyadu 2005a). For example, the spiritual gift of healing was put forward as evidence of such spiritual gifts with the the physical body becoming the preferred medium connecting the transcendent to the physical realm, a site for the full expression of spirituality. Healing, in this case, was achieved through a series of techniques ranging from the laying on of hands, to collective prayer, to forms of exorcism (called deliverance), all attesting to what believers saw as a manifestation of divine presence. The newly assumed religious identity, now known as African Pentecostalism, subsequently spread in Europe and in America, following migration flows. As diasporic communities settled in various host countries, they were able to connect the doctrine through the use of multimedia tools such as video cassettes and tapes (Formenti 2007; Butticci 2012) and thus ensure the survival of the faith even in a country, such as Italy, with a majority Catholic population.

Another important element in the African perspective of Pentecostalism is the role of music, which works in tandem with the Holy Spirit to ensure a vibrant liturgical experience for believers. The musical interludes offer believers the creative space to dance and move as prompted by the Spirit. A wide range of emotions is expressed through the active engagement of physical performances, which become 'a biblical drama of participation in God's history' (Land 2010: 67), or a form of 'spiritual body-building' (Coleman 2000).

For the believer worship is never conceived as a solitary expression of faith, but rather a communal collaborative effort between bodies - a land of unio mystica (Simoni-Wastila 2000) - with the clear goal of providing a route for spiritual transformation (Prosén 2018).
As seen thus far the brand of Pentecostalism practised by African communities privileges the sensory engagement facilitated by the body, which is understood as fulfilling three main functions: as a medium connecting the transcendent to the divine; as a performance site and recipient of divine endowments; and finally, as a body intended, according to its classical theological interpretation, to be a node connecting the communal assembly of worshippers.

The body, in its multifunctionality, becomes an important site of influence within the cyberspace as the religious community adopts and adapts the virtual space to meet its spiritual desires and specific needs.

\section{Spiritualising the virtual space}

Drawing on previous research by Roger Silverstone, Eric Hirsch, and David Morley (1992) on how users 'domesticate' technologies to enable their use to fit more neatly into the routines of daily life, Heidi Campbell (2005) argues that believers too parlay the use of the internet to fit their own religious and spiritual needs. Campbell refers to the 'spiritualising of technology' as a combination of linguistic legitimisation done by religious groups to allow technology to be conceived as a suitable space for religious engagement. For the author the internet becomes a spiritual medium supporting four main rhetorical functions, namely as a spiritual medium, as a sacramental space, as a tool for promoting religion and religious practices, and, finally, as a tool for affirming the religious life. I will now provide a brief outline for each discourse as formulated by the author.

The discourse that sees the internet as a spiritual medium presents the technology as possessing special characteristics that can facilitate the religious experience. Within this space the wires and connections of the 
internet are refashioned as a spiritual conduit for believers; thus the religious repurposing of the internet is seen as a natural part of online engagement (Campbell 2005:10). Moving on to the second discourse, the internet, seen as a sacramental space, conceptualises technology as a space that can be rendered 'holy' through the act of performing specific rituals. Unlike the previous perspective, spirituality is not embedded in the technological infrastructure, but rather is transformed into a space where a divine encounter can occur (p. 11). In the third discourse the internet is seen as a promotional tool for religious practices, more specifically for proselytising endeavours, or what Campbell calls 'e-vangelistic activities' (p. 12). Finally, the fourth discourse which sees the internet as a tool for affirming religious life provides a perspective in which the technology is used by the religious group in practical terms as it gives access to resources that have the potential to edify the believer and facilitate communal religious activities (p. 13).

Heidi Campbell's conceptualisation of the religious discourse around internet use is useful for framing technology not only as a tool for communication, but also as a medium with the potential to shape the religious reality of believers. However, the question that still arises from such reflection is whether online spaces can provide an authentic religious experience such as would take place in physical spaces. This becomes even more relevant during a global pandemic when religious communities can only rely on cyberspace and are not able to supplement religious activities with other physical elements of their liturgy. Undoubtedly questions of 'ritual authenticity' are raised as believers are faced with the evidence of the artificial and constructed nature of cyber worship. What then constitutes an authentic religious ritual? The religious scholar Ronald Grimes argues that 'all ritual, whatever the idiom, is addressed to human participants and uses a technique which attempts to re-structure and integrate the minds and emotions of actors' (1990: 196). This constructivist perspective offers an outlook on religious practices as flexible and adaptable to the existing social environment, including cyberspace, as actors restructure whatever space they are in to fit their spiritual needs.

\section{Theorising the transfer of ritualised practices to virtual churches}

In order to contextualise the digital practice of African Pentecostalism, it is useful to begin with an early account of electronic media and its instrumental role in shaping and promoting the gospel. As several scholars have observed, electronic media such as television have provided an important tool for the dissemination of religious messages (Anderson 2013; Hackett 2009; Hoover et al. 2004). As Kwabena Asamoah-Gyadu notes (2005b: 17 ), televangelists have masterfully honed their skills to bridge the physical distance to the believer watching from home by providing access to the message of the gospel and empowering believers to choose religious teachings that could best answer to their own spiritual needs. By contrast, within the virtual world of cyber churches, Tim Hutchings (2011) notes that Anglican believers were unwilling to perform core ritualistic practices such as the Eucharist online. As it emerges, believers engage in ongoing negotiations by constructing a relationship between activities deemed 'too sacred' to be performed online and those that are viewed as suitable for the online environment. By contrast, in the context of neopagan religious practices taking place in computer-mediated environments, Stephen O'Leary notes that attempts are made by believers to simulate 
and recreate religious spaces by sanctifying the virtual space, to transform it into a theatre where spiritual manifestations can occur (1996: 803). This harks back to the point made by Heidi Campbell as she views the internet as a sacramental space constructed by believers (2005).

For African Pentecostals the sensory engagement brought by music, dance, and exorcism are what could be deemed 'too sacred' to be performed in the cyberspace of Zoom and Free Conference Call. However, as liturgical practices rely solely on digital spaces, I reflect on how these core religious elements are perceived by believers and how ritualistic practices such as the Eucharist are performed within the digital space.

Online worship is shaped by the distinctive properties of the digital environment and, as Heidi Campbell reminds us, believers' conception of technology influences how they negotiate its use (2005: 1). This view echoes James Gibson's formulation of the affordance theory, as he has analysed how animals and human beings relate to the properties found in their environment (Gibson 1979). For James Gibson 'the affordances of the environment are what it offers the animal, what it provides or furnishes, either for good or ill' (p. 127). Affordances refer to both the environment and the actor and, as such, they imply the complementarity of both elements. In Gibson's view affordances are conceived as possibilities and opportunities which require active engagement from actors to produce the intended benefits; thus they are viewed as the properties embedded in the environment that contribute to the reactions that occur (ibid.). In this sense 'an affordance relates attributes of something in the environment to an interactive activity by an agent who has some ability' (Greeno 1994: 338), which means that in
Gibson's view affordances are relative to the ability of their actors. For instance, an affordance for sitting relates to a chair and the actors who approach the said object will have to be able to both perceive its use and be physically adapted to take advantage of its seating potential. Likewise, a believer engaging in religious fellowship online will have to be aware of the properties available in the digital infrastructure to be able to take advantage of them. Affordances, as such, are understood as the applicability of the device and not the inherent properties of such a device. Another important layer of affordances is that these exist independently whether actors decide to use them or not (Sayer 2010), which means that, according to this perspective, the properties of a digital space become relational only when 'triggered' by the user. Don Norman (1988) expanded the discussion of affordances into the context of humancomputer interaction, suggesting that artefacts could be designed to suggest or determine certain forms of use through the notion of 'perceived affordances'. The question was no longer how organisms see, as was the case in Gibson's work, but rather how certain objects could be designed to encourage or constrain specific actions. In Norman's view, agency is placed in the hands of designers who have the ability to enable and constrain certain action possibilities through their design choices (ibid.). Moreover, because affordances are perceived, they are subject to the experience, knowledge, and cultural background of the actor; thus limitations and constraints are not only limited by designers, but can also be self-imposed. In physical fellowship we see and experience people's emotions through their bodily movement and physical expressions, especially during climactic moments of worship. At those moments, spirituality is not only 
expressed through prayer, but also through other physical expressions such as weeping, shouting, raising of hands, kneeling, and other acts that believers perform in submission to the spirit. Thus, emotions can be viewed as emerging through 'embodied and dialogical movements in the interworld between people in their physical and social environment' (Jensen and Pedersen 2016: 84). This view presents affordances not just as objects found in the environment but also as the ways in which human beings relate to and influence one another, which recalls the relational approach as first conceptualised by Gibson.

African Pentecostal churches are characterised by a semi-structured ritual service that is constructed to make it possible for the Holy Spirit to partake in the liturgy; peculiarities such as the emotional delivery of prayers and sermons, the spontaneous verbal and non-verbal responses of believers, dance performances, and music improvisations are all done in the service of the spirit and contribute to the cultural aesthetic that shapes the liturgy. In transferring these elements onto a digital platform, we can observe new modes of digital communication emerging from the new space, as well as the impact it has on the spiritual fulfilment of the worshipper. A central argument within Gibson's theory is that human beings alter their natural surroundings to suit their needs; as such this perspective provides a useful framework to understand how religious communities navigate in digital environments.

\section{Ethnography in the digital religious landscape}

I have been a full member of my African Pentecostal church in northern Italy since I was child and, as I have taken part in many in-person worship services the migration process to a digital platform was very inter- esting to observe. Like ours, many other African Pentecostal churches across the nation were also experiencing the same shift and, as I observed, the new digital arena afforded the communities the unique opportunity to engage in more robust forms of evangelism. Through social-media channels such as Facebook and WhatsApp, churches were able to disseminate the links to their online services to attract new members. Most churches did not require online worshippers to activate their camera, which afforded a certain level of anonymity, especially to new members, who thus had the space and freedom to decide on their own level of active participation. Between February and May 2020, I was able to attend around 50 online church services offered by the various African Pentecostal churches around Italy. The online services included Sunday services, prayer meetings, Bible studies, church conferences, and religious workshops, with each meeting lasting on average two hours. The findings of this study are based on data collected during the Sunday services. Moreover, to bring personal perspectives into the data I conducted 20 interviews, selected by way of snowball sampling. These included perspectives from four leaders (2 ushers, 1 worship leader, 1 pastor) and 16 congregation members. ${ }^{3}$ The interviews were semi-structured with open-ended questions. These were centred around the believers' perspectives as they compared physical and virtual worship practices. All interviews took place on the phone, given the strict social distanc-

3 Ushers are usually in charge of the hospitality team. Depending on the size of the church, their role can encompass a number of responsibilities ranging from cleaning to administrative duties. 
ing measures in place, and they lasted around one hour. The oldest respondent was 65 years old, while the youngest was 21.

The data gathered capture the accounts produced by the research subjects as they operated in the digital space during their worship practices. To this end, attending all worship services was important, as this fully immersive approach afforded me the opportunity to assess the worshippers in their environment and gain a broad understanding of their interaction with each other.

Within the digital communication field, the methodological concept of netnography offers a useful framework to navigate this landscape. According to Robert Kozinets, the hallmark of authentic netnography lies in its humanism, in its 'attention to the details and contexts of human stories and human understandings, of people using technologies' (Kozinets 2016: 4). In developing the concept, Kozinets places great emphasis on its qualitative attributes as he perceives the potential dangers of numerical data to dehumanise individuals by silencing their stories, their insight, and their lived experiences (p. 7). For this reason, the concept of experience as it relates to netnography is central in this research; it refers to 'how it is embodied and lived through sensory and affective moments' (Pink et al. 2016: 20). Experiences are difficult to express and articulate through language, to attempts to understand and interpret their meaning and significance rely on my role as a researcher as I immersed myself in the online worship experiences. This immersive role within a netnographic approach stimulated some ethical reflections regarding my own membership status in the community observed. While the insider role might allow for access and openness, protecting privacy while ensuring methodological transparency become important considerations to be reflected upon. ${ }^{4}$

The contributions made by the respondents, as well as the field notes, highlight the challenges of transferring some of the core aspects of physical worship into a digital space.

In this study, I approach key elements in African Pentecostal liturgical practices, such as music, fellowship, the sacrament of the Eucharist and altar calls by analysing their online transitions. As these usually require physical proximity, I was curious to understand how they were redefined on the digital platform and the impact these would have on the believer.

\section{Affective voices}

Music serves as a very important component in the liturgy of African Pentecostal churches. The incorporation of traditional instruments such as drums, congas, or rattles, as well as melodic vocalisations from choir members, all contribute to the multisensory experience of worship. However, this distinctive cultural element loses its value when transferred to the online environment, as it becomes virtually impossible to synchronise instruments and voices from multiple devices. Issues of sound lag, delays, and distortions represent technical stumbling blocks for believers. When asked what significant changes they noticed as a result of the liturgy moving online, believers expressed the difficulty of engaging in the task of singing collectively. Cora (29 years), is a worship leader at one of the local churches in the north; she has been in the worship ministry since she was sixteen. She was promoted to the new position two

4 Fictional names have been provided and blurred out from images in screenshots. Church names and places of worship have been omitted. 
years ago and has since then overseen the music productions, the choir rehearsals, and training of new talents. As she puts it:

Online worship is really not the same. For starters I am not able to see the expressions on the congregation to see whether the song is having an impact or not. People's attitude during worship can really set the tone and change the atmosphere. In this online space I don't really have that feedback. I can only trust that the Holy Spirit is doing his part.

Cora's church uses the Free Conference application which, compared to Zoom, has a lower bandwidth. As the service can only host a handful of worshippers on camera, believers only worship via audio. Moreover, congregation members are asked to mute their microphones once they join the service, to ensure that background sounds do not disrupt the flow of the service. During prayers, however, the worship leader might ask some of the online congregation to unmute themselves to provide support in the prayer as the feedback response galvanises and provides depth to the worship experience. Cora told me, 'It is really difficult to pray online while only hearing your voice. You easily become tired. The person conducting the prayer needs support from the congregation because this creates momentum for the service.'

The congregation unmute their microphones at specific moments of the service to applaud and to say 'Amen' into their devices and then turn themselves back to mute once this task is completed. As I observed, within the online setting connections are strategically created by believers, who work collaboratively to facilitate emotive moments. This support is entirely voluntary and contingent upon the knowledge of the affordances in the digital landscape, as we will see in the next sections. The voice assumes an important role within the online space as it anchors leaders and congregation to a familiar space of intimacy and safety. In March 2020 Italy experienced one of the highest numbers of COVIDrelated deaths in Europe. ${ }^{5}$ Naturally, the news influenced the church service, and I noticed a general mood shift as members expressed feelings of anxiety and sadness while leading the service. During one of these church services the pastor tried to reassure members by telling the congregation: 'Brethren, do not be anxious about anything; God is in control!' The leader then led the church into a moment of prayer, urging the congregation to speak positive declarations out loud into their devices. The tension that was felt at the beginning changed as believers unmuted their microphones to utter prayers of encouragement and words of affirmation. Many took to the chat box to re-affirm the statements, thus channelling those moments of emotional connections in the chat box as well. In the digital space the physical performance is re-enacted through a soundscape of familiar voices. After the injunction of the pastor to speak positive statements, the feelings of the service changed, and the congregation appeared to be more hopeful and optimistic. The feelings of anxiety and then euphoria were appraised and negotiated in a relational and reciprocal manner to become emotionally contagious, a space where affect can flow. However, while this clearly changed the mood of the service, it

5 According to ISTAT, until 31 March 2020, deaths increased from 65,592 (average period 2015-19) to 90,946 , in 2020. The excess of the deaths is 25,354 units, $54 \%$ of these being COVID-19 diagnosed deaths $(13,710)$. ISTAT 2020. 
is difficult to know whether people's anxieties were quelled, or whether this was part of going along with the rules and expectations of emotion that become part of the religious experience.

\section{Worship in the chat box}

As already established, emotional ties can also work through the gathering of voices. However, as I attended many services, it became apparent that the chat box functioned as an important space for the gathering and creation of what I call 'digital spiritual hype people. 6 As the services are not recorded for later viewing, members must stay present in the moment. Thus, the chat box provides the space where that spontaneity is expressed in real time and where believers can rally their support behind a specific message they endorse, or a moment in the service they find particularly interesting. During the virtual liturgy, moments of deep cognitive engagement are expressed through emojis, such as hand-clap emojis or fire emojis, and at spe-

6 In her analysis of praise dance, Tuija Hovi (2011) introduces the term 'spiritual cheerleading' to describe the unique value that praise dance performers bring to the Christian liturgy. Whereas in physical worship praise dancers are professionals who are tasked with creating an atmosphere that can invite the presence of the Holy Spirit, in the virtual reality of worship it is the individual members who voluntarily render their support in a way that becomes similar to the vocal support that hip-hop hype men provide to MC/Emcee (Master of Ceremony or Microphone Controller). In hip-hop music the hype man supports the primary rapper by injecting, reaffirming and exclaiming key points in the musical performance with the sole purpose of stirring excitement in the crowd. A similar dynamism can be observed in the digital space of worship between believers and religious speakers. cific points when a message was particularly evocative believers would type words like 'hmmm', 'yaaaaaaaaassss', 'omg!!' or 'Amen!!!'. Believers become 'digital spiritual hype men' who not only provide positive feedback for the speakers, but can potentially influence other believers to endorse the message of the speaker (Figure 1).

In offline services this spontaneity is expressed by the believers lifting up their hands, or standing up and clapping, nodding or shouting 'hallelujah!' in response to those emotive moments during the service. However, in online spaces those physical responses cannot be fully expressed because of the limitations of the mute button, which is often applied on devices to avoid sonic disruptions. Therefore, believers make use of the chat box to funnel their emotions as they flow. These moments of digital community gathering encourage more people to engage and take part in the conversation, which in turn provides a constant loop of positive feedback between the leader and the congregation.

Joe, who is 27 years old and is in charge of the youth ministry, confessed to me that the short messages left in the chat box are encouraging to him because they reflect the level of engagement and connection of the audience he is speaking to. In fact, unlike moments of prayer and singing, which can be subject to delays, lags, and sound distortions, the chat box is the place where synchronous reactions happen in real time, albeit silently. These reactions are not only in response to the person leading the service, but also to messages left by other members, which mimics offline church interactions. The perceived affordance of the chat box provides the emotional gathering that believers need in order to recreate the offline worship experience. The option to type a text or even the vast selection of emojis are all features that have been 


\section{Close}

Chat

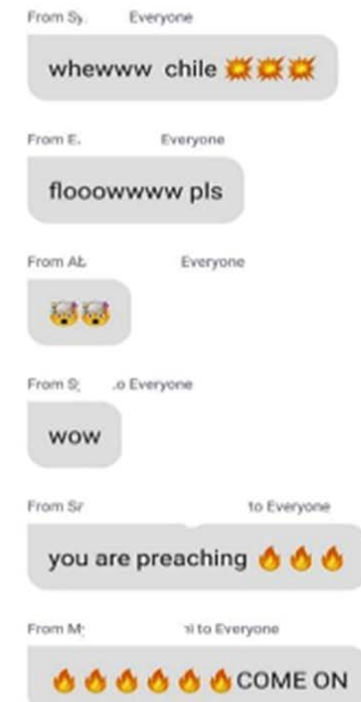

Send to: Everyone $~$

Your text can be seen by everyone Send

\section{Close}

\section{Chat}

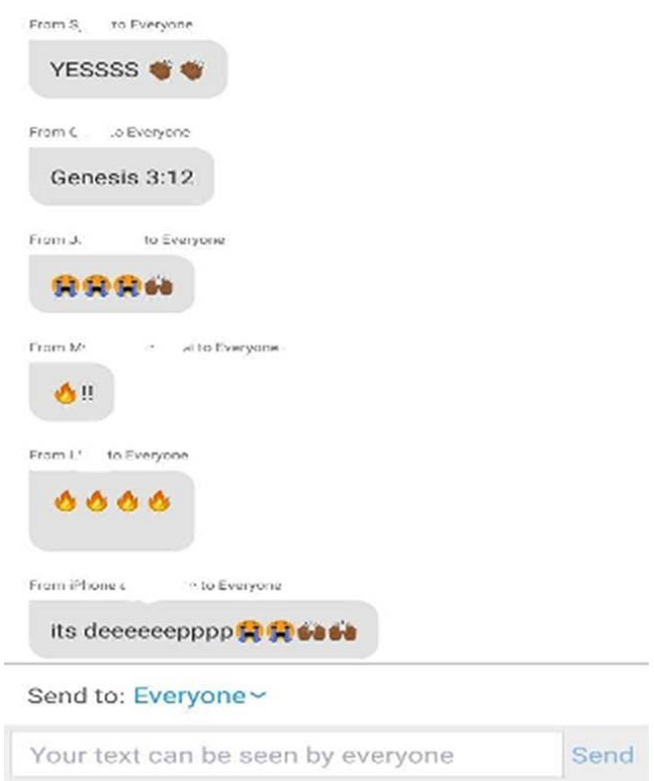

\section{Close}

Chat

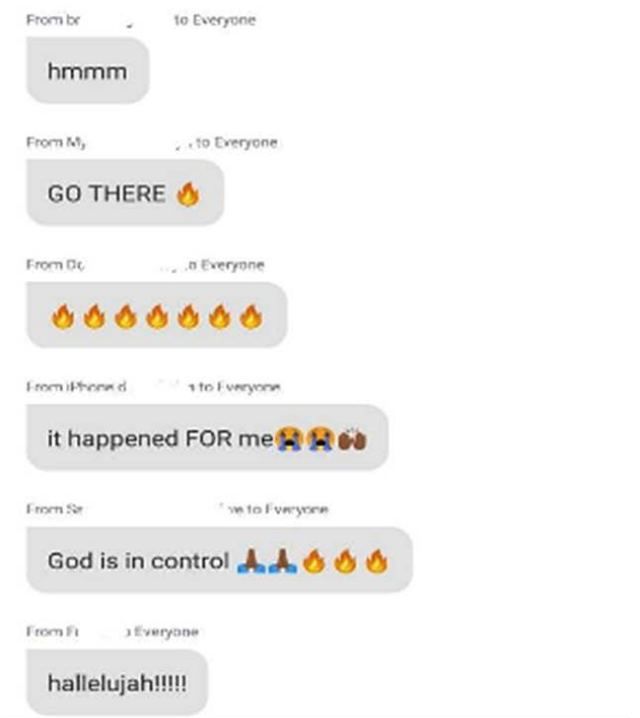

Send to: Everyone $~$

Your text can be seen by everyone

Senc

\section{Close}

Chat

\section{STAND!!!}
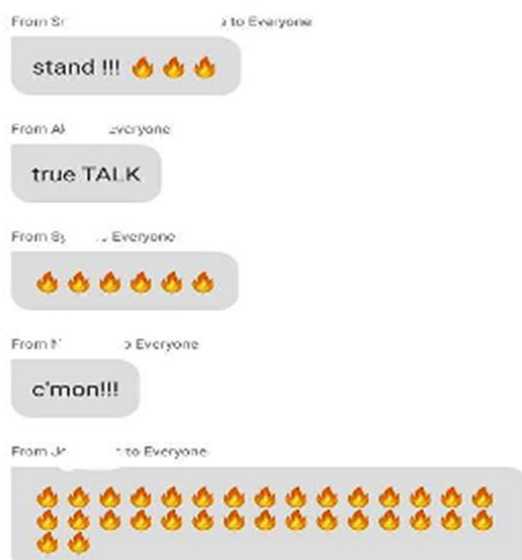

Fromb.

-o Everpone

Send to: Everyone $~$

Your text can be seen by everyone Send

Figure 1. The chat box as a space where digital spiritual hype people gather. 
created by the app designers and developers, who have made them available to the online user, as Norman (1990) envisioned.

However, we can see that the level of engagement the chat box provides can also be viewed as a 'social affordance.' In fact, according to Gibson (1979), the richest forms of affordances available in the environment are those presented by other individuals. The way people behave or act in a specific space provides important cues for others. In this case the commentary in the chat box can prompt others to respond and engage more freely, thus creating a sense of community. It is important to note that the use of, and the language expressed in, the chat box are a reflection of the social background of believers. As young people are more likely to use the tool, the social meanings of the emojis used, as well as the use of language influenced by American popular culture, all contribute to a layering of experiences that can be observed in a digital setting. As we will see in the next section, depending on the age group, believers achieve a different online worship experience, since not all believers are aware of the affordance of the chat box.

\section{Generational gaps}

As anticipated, affordances are not engaged with universally. There is a clear contrast between the way young people use the chat box and how older believers approach digital tools. While talking to some of the older people I observed that for them connecting with each other through the chat box was not an important aspect of the worship experience. Gina, who is 56 , said to me: 'I never use the comment box. What is the point in typing a hand clap (emoji)?'

There is certainly a generational element that characterises the relationship between the affordances presented on the digital platform and the user's ability to take advantage of them. Gina's generation is not accustomed to the use of emojis and she did not see the point in communicating her reactions during key moments in the service. This was something she did not want to externalise on a digital platform as she felt she could not derive any benefit from it.

Having participated in different virtual services I could ascertain the ones that had younger members in the congregation by scrolling through the chat box and reviewing the types of emojis used. The most popular are prayer-hands emojis, handclap emojis, crying emojis, fire emojis, laughing emojis, and high-five emojis.

However, irrespective of the availability and possibilities for actions presented on the digital platform, we can see that the digital platform has different affordances for different people as these are understood in relation to what believers do with them, rather than the qualities they possess.

Gina's reluctance to use emojis can be viewed in different ways.

On the one hand, according to Ian Hutchby's concept of 'communicative affordances', we can say that the affordances of an object may differ between species (2001). While Hutchby is talking about affordances in the animal kingdom, we may understand affordances in terms of generations, and how some have grown accustomed to the use of specific forms of technology compared to others. On the other hand, we can understand Gina's reluctance to use the chat box in terms of William Gaver's notion that affordances are to be actively explored by the individual (1996 in Bucher and Helmond 2018). Individuals can decide to explore the environment around them and make use of the affordances available to them. In other words, the agentic power is with the individual who, having explored the environment around them, may decide 
to use the affordances or not. So, in this case it did not matter how sophisticated the digital platform was: Gina's reluctance to use the chat box suggests that the emotional benefit it afforded to other worshippers did not apply to her.

Gina's case also contradicts Norman's (1990) view of affordances as technologically determinist, as her use of the chat box becomes a key governing force for how believers express their spirituality and emotions while worshipping online. It is clear that not all believers use the chat box to contribute to the affective environment of the online church service. This should not be viewed as powerlessness or failure to perceive the embedded values in this technology. For people like Gina intimate connections with the divine and with the congregations can occur in other ways, perhaps through the voices of the congregation in prayer, as we have seen in the first section. Some worshippers have perceived the affordance of the chat box and the value it brings as an outlet through which affect can be communicated. On the other hand, other worshippers might not even perceive the intended uses of the features on the digital platform because they are less technologically savvy. In some instances, some of the worshippers thought that the notification sound from the messages in the chat box was disruptive to the service if they did not have the option of muting it (or did not know how to). As Mara (6o years) told me: 'It was my daughter who showed me that you could also send messages on the platform! I didn't realise that unlike WhatsApp groups, on Zoom you could actually send a message to specific people without others being able to see it.' Mara refers to a moment during a service where she had accidentally left her microphone on. She then received a private message from her daughter who was following the Sunday service from another country, telling her to mute herself as they could hear her conversation with her neighbour during the service.

In exploring the different features available to believers worshipping on online platforms, we can agree with Norman (1990: 41) that 'affordances are of little use if they are not visible to the users'. Gina's and Mara's perspectives show that believers become 'digital spiritual hype men' when they are able to probe the digital territory and detect the affordances that will become useful for the collective digital worship experience.

\section{The challenges posed by digital spiritual hype people}

Most of the online church services I have attended were delivered through audio. Occasionally the worship leader or the minister would turn their camera on; however, this was never imposed on the congregation. When I asked one of the deacons why this was the case, he replied that 'people don't feel at ease in front of the camera. They might feel the pressure to act a certain way, but God is interested in the heart of a person'. On the other hand, Cora, the worship leader, complained about 'people not caring and not being disciplined enough while worshipping online'. In her view there was a 'lack of accountability' as she referred to specific moments during the service where some members 'were caught' engaging in other activities. Phone conversations, kitchen sounds and television programmes are some of the noises that have accidentally found their way into the online church service. I recall a mortifying episode of a fellow worshipper snoring in the middle of an early morning worship service on Zoom. The host of the meeting had asked some members to provide support in the prayer; however, a brief moment of silence exposed a believer who had fallen asleep during the 
service and had begun to snore heavily into the microphone. The incident interrupted the affective flow created in the digital environment as members began to giggle and laugh. The host of the meeting attempted to restore order by muting all microphones and subsequently sent a private message to the transgressor. Having now noticed the wrongdoing, the member used the chat box to send a public apology regarding the incident (Figure 2). Interestingly, in a physical worship environment, this apology would not have been possible without interrupting the service.

This incident highlights the fact that not all believers can be 'good spiritual hype people' and in some cases, can actually be disruptive to the religious service. Going back to Ronald Grimes's formulation of rituals as restructured through techniques that integrate the minds and emotions of actors (1990: 196), it can be argued that,

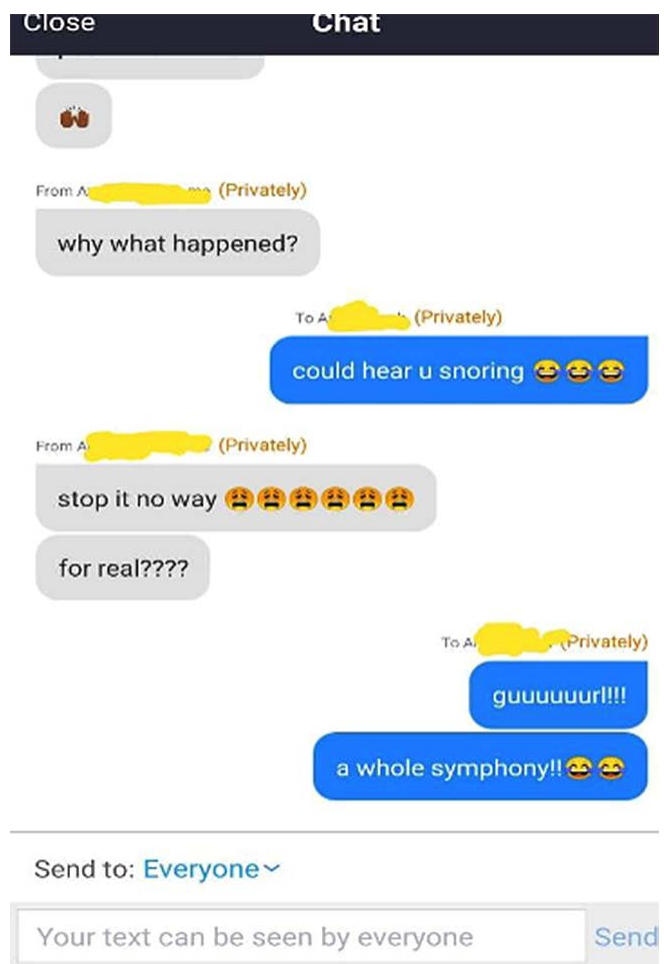

for that believer, the digital space had not been coded as a genuine religious space where the emotional performance of religion could take place. In other words, the digital space had not become a 'sacramental space' (Campbell 2005), and as a result, it could not be rendered entirely 'holy' through the religious fellowship. An important caveat emerges from this, that is, for fellowship to occur within the digital space, the technology must undergo a process of 'spiritualisation' as Campbell argues. This legitimisation allows the cyber space to be conceived by believers as a bona fide space of worship. By establishing consensus on rules of collective engagement believers can approach the cyber space as an extension of the offline worship space. However, this reimaging and restructuring is not always successful. When Cora complains that 'online worship is not the same thing' or that there is 'lack of accountability', I
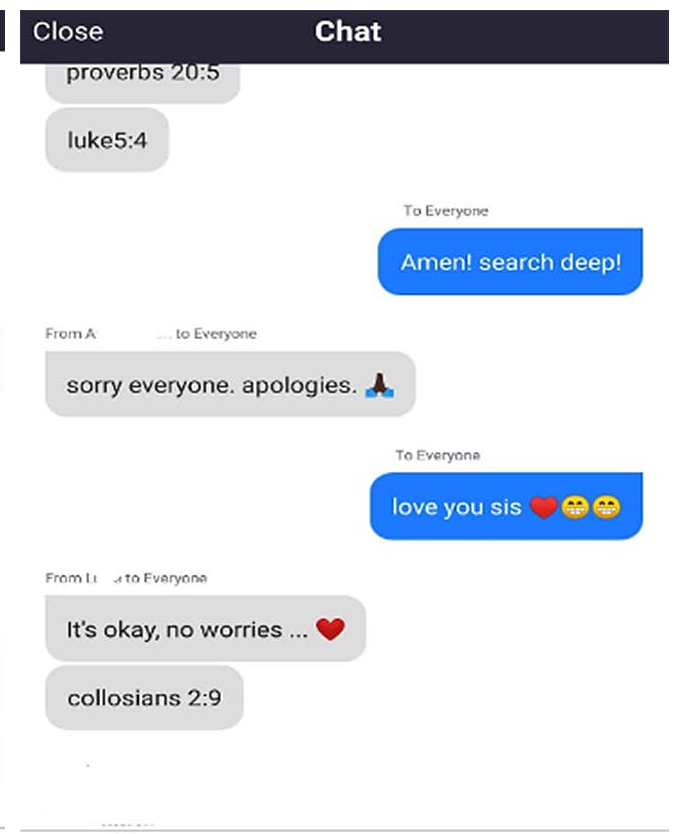

Send to: Everyone`

Your text can be seen by everyone Send

Figure 2. Believer using the chat box to apologise. 
sense that her frustrations are partly connected to the lack of engagement and social surveillance which have traditionally contributed to religious performance. Interestingly, however, as I noticed, even in the absence of such social surveillance some of the power dynamics found in offline spaces are also replicated online as the leaders are in control of the Zoom hosting rights such as the mute button or recording privileges. Some of these powers would then be shared with ushers, who as meeting co-hosts would perform the same hospitality or gatekeeping duties as they normally would in physical services. Such 'cyber duties' included allowing attendees into the meeting room, or noting in the chat box scriptures mentioned by the pastors so that believers could revisit them in their private moments of study.

As mentioned before, emotional connections online are achieved through collaboration between leaders and congregation members. A worship service hosted on Zoom and Free Conference Call can be subject to sonic disruptions, which can ultimately threaten the quality of the service. Hence leaders and meeting hosts are quick to turn to the affordance of the mute button to restore order into the service. In physical spaces a person cannot actually mute another person, which demonstrates a rare instance of this specific affordance being available only in the digital space.

\section{Digital altar calls and digital Eucharist}

In physical church services, altar calls are those moments where believers respond to an appeal by a minister to come forward to the altar or pulpit to freely commit themselves to Christ or receive physical or spiritual healing. The response to an altar call is never imposed, as believers are not actually called to the altar. Nevertheless, they could be viewed as a form of emotional priming following a moment of deep emotive connection with the music played, or a particularly engaging message dispensed by the preacher. During such moments worshippers can enter a trance-like state, experience brief instances of psychosis, and use glossolalia. For the believer, the altar call represents a unique opportunity to connect with the divine. During the online worship one of the preachers asked the congregation to place their hands on any part of their bodies that was feeling unwell. In other services the preacher connected to the congregation by saying: 'stretch forth your hand and touch the screen (of the device) as I pray for you. The Holy Spirit is not interested in the distance between us. He can still perform his miracles'. Here, rather than being an obstacle, the screen is re-appropriated as a tool for the very physical connection, connecting the pastor to the believers, and believers to the Holy Spirit. Within this space the digital environment is refashioned as a spiritual conduit for the congregation as wires, connections, and the technological infrastructure become a 'sacramental space' (Campbell 2005) to facilitate the religious experience of spiritual healing. Online church services can never fully substitute for physical church services: typically, believers who participate in digital church services do so as an experience complementary to their offline engagement (Hutchings 2011). However, in this case, the only choice available to believers was online worship. Therefore, it becomes important to find creative solutions for re-contextualising the meaning of worship and to re-imagine the online arena as a space where spiritual moments can take place.

Another example of re-imagination of the online space took place during Easter Sunday as believers celebrated the sacrament of the Eucharist (or Holy Communion). To perform the religious ritual 
the preacher asked believers to hold a cup of water or juice in one hand, and a piece of bread or cake in the other, as he imparted 'grace and anointing' on both items. After a moment of collective prayer, the preacher encouraged believers to consume the religious feast as he read a biblical passage. As seen in other examples of Christian groups engaging in online worship, the sacrament of the Eucharist becomes a contentious issue as believers and religious leaders question the legitimacy of the ritual when this takes place in cyberspace (Hutchings 2011; The Vatican 2002). For Pentecostals, however, the Holy Communion is a symbolic reminder of the sacrifice of Christ, and because the doctrine emphasises a direct rapport with the Holy Spirit, the ritual becomes a re-enactment of the believer's relationship with the divine. Perhaps because of this reasoning, believers did not experience a stark contrast between the ways in which the ritual occurred online, compared to how it traditionally takes place offline. In many conversations with believers the term 'personal journey with the Holy Spirit' was often used to underscore how members understood their religiosity, noting that for them the online worship service was just one of the many ways in which they connected with the divine. Thus their own religious lifestyle (and not the cyberspace platform) was to be kept 'holy' to facilitate divine connection.

\section{Conclusions}

This article has analysed the unique ways in which African Pentecostal communities in Italy have used digital platforms for their religious practices during the coronavirus global pandemic. The traditional liturgy relies heavily on sensory and aesthetic properties. However, in the online environment, as worshippers attempt to recreate some of these elements, they soon discover that issues of audio lag, delays, and distortions pose challenges to the synchronous worship experience. Believers attempt to circumvent this obstacle by working collaboratively to become 'digital spiritual hype people' by reappropriating the affordances available in the digital infrastructure to recreate affective moments in the digital space. As shown, affect can become manifest from the gathering of voices online, then subsequently, it is funnelled in the chat box for all believers to see and engage with, thus creating a constant loop of feedback responses and collective engagement. Overall, the digital platform presents different affordances for different people, as I argue that affordances are presented as what believers can do with the digital tools. For example, while the affordance of the chat box provides the congregation with a voice, the mute button is the tool used by leaders to restore order during the service. The chat box on the one hand, and the mute button on the other, highlight some of the existing power dynamics that migrate to the online environment. The Holy Spirit, a focal point for African Pentecostals, is understood as an embedded element in the digital space as religious leaders refashion the technological infrastructures, the wires, the screen, and internet connections as a 'sacramental space' (Campbell 2005) to channel miraculous healing and facilitate divine encounter. When it comes to religious rituals, the sacrament of the Eucharist is performed as a bona fide religious ritual because it is understood as a symbolic representation of the believer's personal journey with the Holy Spirit.

Many social interactions have migrated to online spaces as a result of the impact of the COVID-19 global pandemic. These digital platforms have in turn had to expand and adapt their scope to new emerging 
needs, including spiritual ones. This study has demonstrated that these platforms, which were designed and intended for secular necessities, can, in part, be repurposed and adapted to religious needs to serve as sacred spaces where religious gatherings can take place.

\section{Giuseppina Addo holds} a master's degree in media and communication studies and a bachelor's degree in international migration and ethnic relations both completed at Malmö University in Sweden. Following a successful thesis discussion where she presented

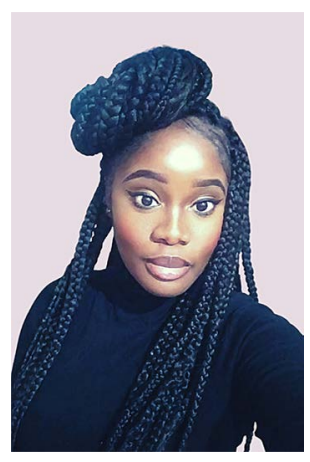
her study on the digital liturgical practices of African Pentecostals during COVID-19, she further expanded her research interest to investigate the interface between digital media, religion, and affect. She currently works as a researcher at the Malmö University Data Society programme, where she contributes to research on the challenges and opportunities arising from digitisation and datafication.

\section{Bibliography}

Anderson, Allan. 2013. An Introduction to Pentecostalism (Cambridge University Press), doi: $<$ doi.org/10.1017/CBO9781139524063>.

Asamoah-Gyadu, J. Kwabena. 2005a. African Charismatics: Current Developments within Independent Indigenous Pentecostalism in Ghana (Boston: Brill).

- - 2005b. 'Anointing through the screen: neo-Pentecostalism and televised Christianity in Ghana', Studies in World Christianity 11: 9-28, doi: <10.3366/ swc.2005.11.1.9>.

Bucher, Taina, and Anne Helmond. 2018. 'The affordances of social media platforms', in The SAGE Handbook of Social Media, eds. Jean Burgess, Alice Marwick, and Thomas Poell (Thousand Oaks, CA: SAGE Publications), 233-53.

Butticci, Annalisa. 2012. 'Il Dio di Davide: musica e danza della tradizione pentecostale africana, Religioni e Società: Rivista di scienze sociali della religione 27(73): 59-67.

Campbell, Heidi. 2005. 'Spiritualizing the internet: uncovering discourses and narratives of religious internet usage', Online - Heidelberg Journal of Religions on the Internet 1(1): 1-26, doi: <https://doi.org/10.11588/ heidok.00005824>.

Coleman, Simon. 2000. The Globalisation of Charismatic Christianity (Cambridge UPs).

Döveling, Katrin, Anu A. Harju, and Denise Sommer. 2018. 'From mediatized emotion to digital affect cultures: new technologies and global flows of emotion', Social Media + Society 4(1), doi: <https://doi. org/10.1177/2056305117743141>.

Formenti, Ambra. 2007. 'Chiese pentecostali africane a Torino', Afriche e Orienti 9(3-4): 101-15.

Gaver, William W. 1996. 'Situating action II. Affordances for interaction: the social is material for design', Ecological Psychology 8: 111-29, doi: <10.1207/ S15326969ecoo802_2>.

Gibson, James J. 1979. The Ecological Approach to Visual Perception (New York: Psychology Press).

Greeno, J. G. 1994. 'Gibson's affordances', Psychological Review 101(2): 336-42.

Grimes, Ronald L. 1990. Ritual Criticism: Case Study in its Practice, Essays on its Theory (Colombia: University of South Carolina Press).

Hackett, Rosalind I. J. 2009. 'The new virtual (inter)face of African Pentecostalism, Global Perspectives on Pentecostalism 46: 496-503, doi: $<10.1007 / \mathrm{s} 12115-009-9254-1>$.

Hovi, Tuija. 2011. 'Praising as bodily practice: the neocharismatic culture of celebration', Religion and the Body, ed. Tore Ahlbäck, Scripta Instituti Donneriani Aboensis 23 (Turku: Donner Institute), 129-40, doi: $<$ doi.org/10.30674/scripta.67384>.

Hoover, S. M., L. S. Clark, and L. Rainier. 2004: Faith Online (Washington, DC: Pew Internet \& American Life Project).

Hutchby, Ian. 2001. 'Technologies, texts and affordances', Sociology 35(2): 441-56.

Hutchings, Tim. 2011. 'Contemporary religious community and the online church', Information, Communication \& Society 14(8): 1118-35, <doi.org/10.1080/13691 18X.2011.591410>. 
ISTAT. 2020. 'Impact of the COVID-19 epidemic on the total mortality of the resident population in the first quarter of 2020', Istituto Nazionale di Statistica, 4.5.2020, $<$ https://www.istat.it/it/files/2020/05/IstatISS_-eng.pdf $>$ (accessed 24.8.2021).

Jensen, Thomas Wiben, and Sarah Bro Pedersen. 2016. 'Affect and affordances: the role of action and emotion in social interaction, Cognitive Semiotics 9(1): 79-103, doi: <https://doi.org/10.1515/ cogsem-2016-0003>.

Kozinets, Robert W. 2016. Netnography: Redifined (London: SAGE Publications).

Land, Steven Jack. 2010. Pentecostal Spirituality: A Passion for the Kingdom (Cleveland: Ohio CPT Press).

Norman, Don. 1988. The Psychology of Everyday Things (New York: Basic Books).

- - . 1990. The Design of Everyday Things (New York: Doubleday Business).

- - 1999. 'Affordance, conventions, and design', Interaction 6: 38-42, doi: $<10.1145 / 301153.301168>$.

O'Leary, Stephen. 1996. 'Cyberspace as sacred space: communicating religion on computer networks', Journal of the American Academy of Religion 64: 781-808.

Pink Sarah, Heather Horst, John Postill, Larissa Hjorth, Tania Lewis, and Jo Tacchi. 2016. Digital Ethnography (London: SAGE).

Prosén, Martina. 2018. 'Songs that carry transformation: Pentecostal praise and worship rituals in Nairobi, Kenya', Church and Mission Studies 35: 265-85, doi: < doi. org/10.1163/15733831-12341570>.

Sayer, Andrew. 2010. Method in Social Science: A Realist Approach, 2nd rev. edn (New York: Routledge).

Silverstone, Roger, Eric Hirsch, and David Morley. 1992. 'Information and communication technologies and the moral economy of the household', in Consuming Technologies: Media and Information in Domestic Spaces, eds. Roger Silverstone and Eric Hirsch (London: Routledge), 15-31.

Simoni-Wastila, Henry. 2000. 'Unio mystica and particularity: can individuals merge with the One?', Journal of the American Academy of Religion 68(4): 857-78.

The Vatican. 2002. 'The Church and internet', Pontifical Council for Social
Communications, <http://www.vatican. va/roman_curia/pontifical_councils/pccs/ documents/rc_pc_pccs_doc_20020228_ church-internet_en.html> (accessed 18.4.2021). 